\title{
Nonlinear Analysis of Reinforced Concrete Beam Bending Failure Experimentation Based on ABAQUS
}

\author{
Deng Sihua ${ }^{1, a}$, Qie Ze $\mathrm{e}^{1, \mathrm{~b}}$ Wang $\mathrm{Li}^{1, \mathrm{C}}$ \\ ${ }^{1}$ Beijing University of Civil Engineering and Architecture, Beijing China 100044 \\ a13366015526@163.com, bieze@hotmail.com, ciamwangli83@yahoo.com.cn
}

Keywords: Nonlinear analysis; Reinforced concrete beam bending failure experimentation; Finite element analysis.

\begin{abstract}
The nonlinear analysis of a reinforced concrete beam was conducted based on the finite element analysis software ABAQUS. In this simply supported beam analysis, the plasticity model of concrete damage in ABAQUS has been introduced thoroughly. Finally, the results of the experimentation and the ABAQUS analysis were compared in a diagram, accordingly reasons of the result difference between the two methods were discussed, which can be a useful reference for the further study of the nonlinear analysis of reinforced concrete.
\end{abstract}

\section{Introduction}

With the continuous development of finite element theory and computer technology, the development of finite element analysis software is maturing. ABAQUS, as one of the largest universal finite element analysis software, is increasingly commonly used in research works and engineering. Because not only does it have high speed, high accuracy and low cost analysis of numerical calculation of finite element analysis software, but also has a more user-friendly operator interface and visualization results, especially when it is used in the nonlinear analysis of reinforced concrete structure ${ }^{[1]}$.

Now, by a comparison of the test result data and the simulation result data of ABAQUS, we make a discussion and analysis on the differences, which can be a useful reference for the further study of the finite element analysis on ABAQUS.

\section{Methods}

\subsection{ABAQUS nonlinear analysis of reinforced concrete}

The source of nonlinearity of reinforced concrete structures is mainly divided into three categories $^{[2]}$ : material nonlinearity, geometric nonlinearity and boundary conditions nonlinear. Material nonlinearity refers not only to consider the elastic properties of the linear phase, but also consider that the nonlinear stage of its plastic properties when we analyze the mechanical properties of the steel and concrete. In ABAQUS, we achieve the nonlinear characteristics of the material by definition of steel and concrete constitutive model. In the elastic stage, we enter elastic modulus and Poisson's ratio of the two materials; But the definition of the plastic stage is different: reinforced simply enter the plastic stage of stress-strain relationship, however, there are three models can be chosen in the concrete plastic stage ${ }^{[3]}$ : Concrete Smeared Cracking, Concrete Damaged Plasticity and Cracking model for concrete in ABAQUS/Explicit. The Plasticity model of concrete damage has certain advantages: it can be used in the individual load, cyclic loading, dynamic loading and so on. It has good convergence, so Plasticity model of concrete damage for concrete plastic definition is commonly used.

The change of boundary conditions (including the contact between the members) in the analysis process will produce boundary nonlinear problems. Frictional contact of the steel and concrete in ABAQUS is achieved by Embedded technology. Reinforced unit is embedded in concrete unit by Embedded technology ${ }^{[4]}$.

Geometric nonlinearity occurs in the case of the size of the displacement affect the structural response. It only needs to add NLGEOM parameters to STEP options. But the general nonlinear 
static analysis does not require to select NLGEOM parameters, in order to avoid the tedious amount of computation.

\subsection{Analysis instance of simply supported beam made by reinforced concrete}

\subsubsection{The establishment of model}

This simply supported beam is $1500 \mathrm{~mm}$ long, with a section of $180 \mathrm{~mm} \times 100 \mathrm{~mm}$. the Concrete strength is C25. Longitudinal reinforcement and stirrups adopted HPB235 reinforced: see Figure 1 for specific circumstances. In ABAQUS, the concrete adopted C3D8R element and the reinforced used T3D2 element. We embedded reinforced in concrete element to simulate the bonding relationship between the reinforced and concrete. In case of stress concentration in beam loading surface and supports when we apply the load on the beam, we set steel gasket in the acting position of the force and supports to increase the contact area and stiffness: see Figure 2 for model diagram.

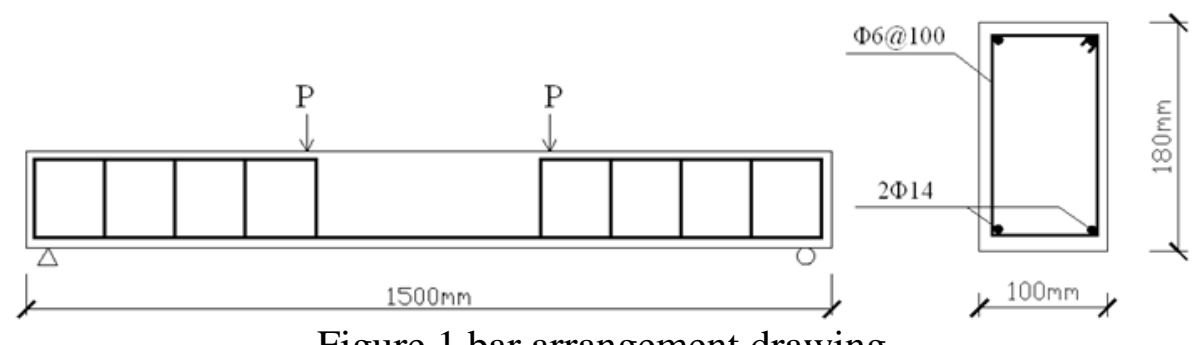

Figure 1 bar arrangement drawing

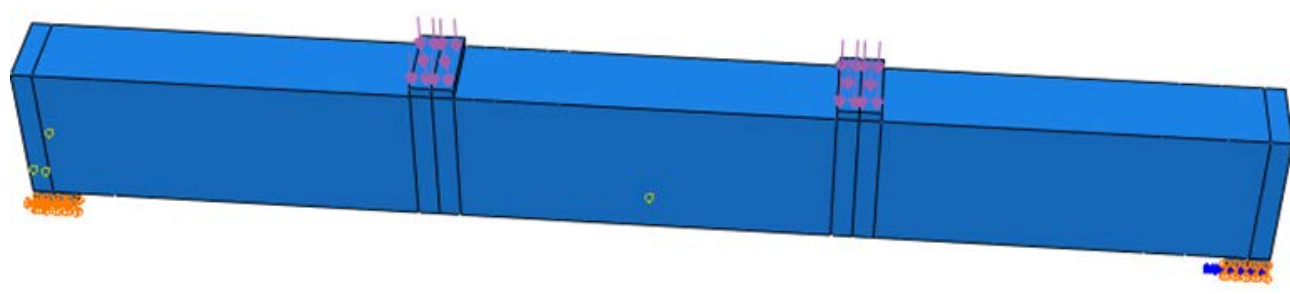

Figure 2 model diagram

\subsubsection{Calculation of the relevant parameters of reinforced concrete}

The constitutive model of Reinforcement uses bilinear model: the slope of the rising stage_-modulus of elasticity of steel, namely Es_—is $245 \mathrm{GPa}$, and horizontal stage is from 0.001 to 0.006 of yield strain, with the yield stress of 245MPa correspondingly. Constitutive model for concrete axial compressive is based on the model formula suggested by E.Hognestad ${ }^{[5]}$ :

$\sigma=\left\{\begin{array}{rc}\mathrm{f}_{\mathrm{c}}\left[2 \frac{\varepsilon}{\varepsilon_{0}}-\left(\frac{\varepsilon}{\varepsilon_{0}}\right)^{2}\right], & \varepsilon \leq \varepsilon_{0} \\ \mathrm{f}_{\mathrm{c}}\left[1-0.15 \frac{\varepsilon-\varepsilon_{0}}{\varepsilon_{\mathrm{u}}-\varepsilon_{0}}\right], & \varepsilon_{0} \leq \varepsilon \leq \varepsilon_{\mathrm{u}}\end{array}\right.$

In which, uniaxial tensile strength of concrete is $14.2 \mathrm{MPa}$, yield strain is 0.002 , and ultimate strain is 0.0038 .

The constitutive model of concrete unidirectional tensile uses the formula in specification for design of reinforced concrete structure ${ }^{[6]}$ :

$\sigma=\left\{\begin{array}{c}\mathrm{f}_{\mathrm{t}}\left[1.2 \frac{\varepsilon}{\varepsilon_{\mathrm{t}}}-0.2\left(\frac{\varepsilon}{\varepsilon_{\mathrm{t}}}\right)^{6}\right], \varepsilon \leq \varepsilon_{\mathrm{t}} \\ \mathrm{f}_{\mathrm{t}} \frac{\frac{\varepsilon}{\varepsilon_{\mathrm{t}}}}{\mathrm{a}_{\mathrm{t}}\left(\frac{\varepsilon}{\varepsilon_{\mathrm{t}}}-1\right)^{1.7}+\frac{\varepsilon}{\varepsilon_{\mathrm{t}}}}, \varepsilon \geq \varepsilon_{\mathrm{t}}\end{array}\right.$

In which, uniaxial tensile strength of concrete is $1.51 \mathrm{MPa}$, and concrete peak tensile strain is $73.64 \times 10^{-6}$.

\section{Analysis results}

\subsection{Experiment}

By design calculations, we determined the cross-sectional dimension, material parameters, amount of reinforcing steel and other data of the beam, carrying out Simply supported at both ends and 
loads applying on two points, Test model shown in Figure 1. When testing, we apply stage loading in accordance with calculated capacity and the load on each point is the same. By controlling loading speed, we use a dial indicator and displacement gauge to measure the deflection of reinforced concrete beam, recording corresponding load, while observing the beam cracks and destruction till the beam completely destroyed. Drawn load-deflection curve shown in Figure 3.

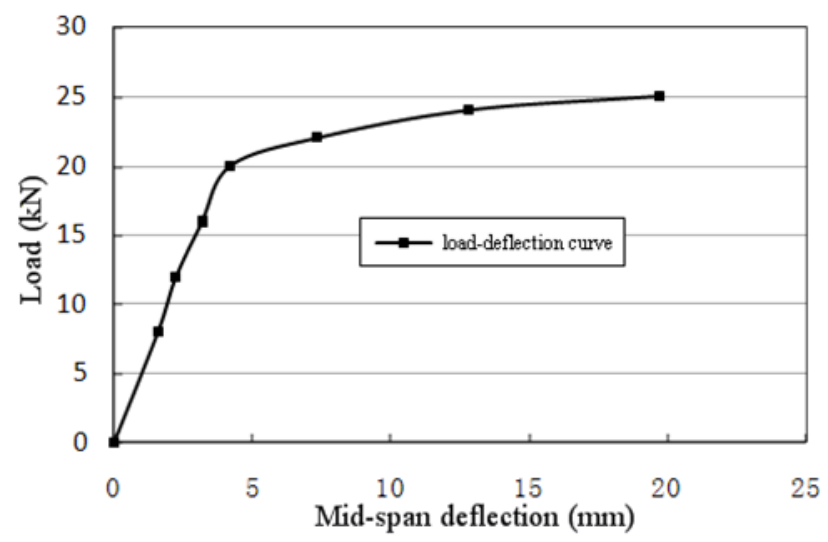

Figure 3 load-deflection curve

\subsection{Simulation}

We apply 3.2MPa of uniform load on the gasket in simply supported beam of reinforced concrete, namely, a force of $16 \mathrm{kN}$. See Figure 4 for the result of analysis of Mises stress. The maximum of Mises stress, $41.16 \mathrm{MPa}$, appears in the gasket of support. Around the gasket of applying force also appears bigger stress, changing from 3MPa to 14MPa. Similar with arched truss force model of beam with web reinforcement, the stress distribution between two supports forms Stress arch. Since the force of beam shoulder is small, Mises stress is smaller, and Mises stress in the bottom of beam is smaller under the effect of reinforcement.

We apply 3.2MPa of uniform load on the gasket in simply supported beam of reinforced concrete, namely, a force of $16 \mathrm{kN}$, therefore, by calculation, the displacement of nodes in the middle of the beam is $2.210 \mathrm{~mm}$ (see Figure 5), and its time variation is shown in Figure 6. As we can see, with the increase of calculation time, span deflection growth gradually accelerated. Since reinforced concrete in the elastic phase have high strength and strong rigidity, the amount of change in mid-span of deflection is small in the beginning; after entering the plastic stage, the material property of reinforced concrete declines, and therefore the acceleration of the deflection of the beam speeds up, thereby forming an acceleration in the mid-span deflection curve. This shows that the simulation is of a reliable theoretical basis, very credible.

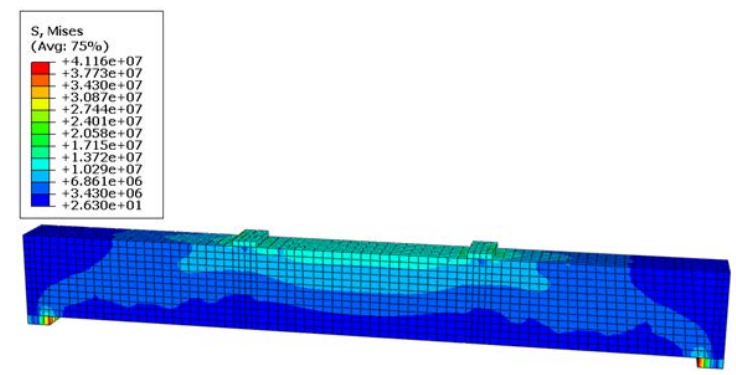

Figure 4 beam stress

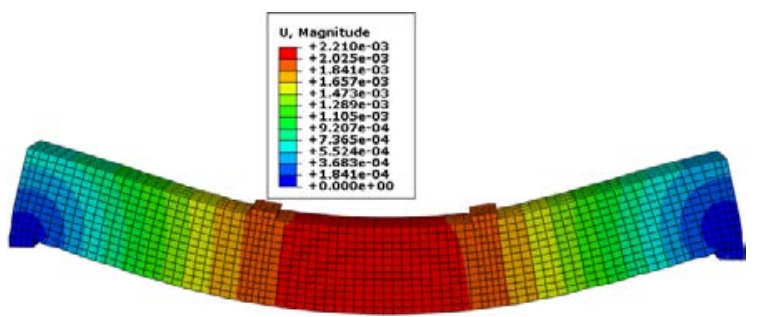

Figure 5 beam displacement 


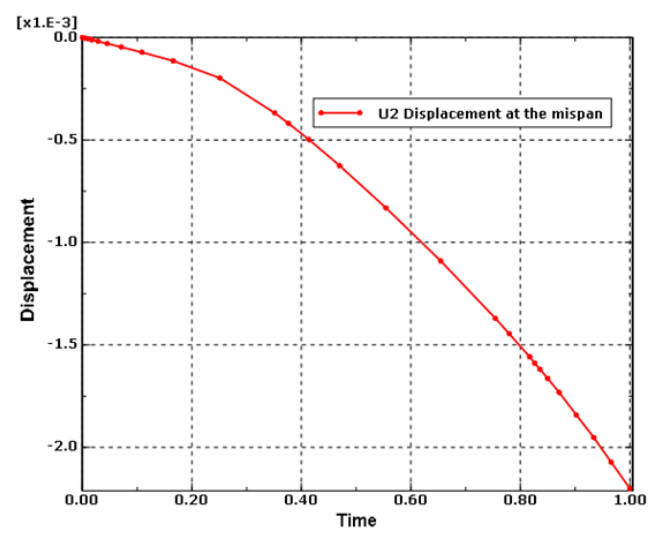

Figure 6 mid-span displacement-time curve

\section{Comparison and Discussion}

In order to carry out analysis and comparison between numerical simulation and test results conveniently, we use ABAQUS to apply the load step by step, calculating the result, getting the data of mid-span deflection and drawing the graph. See Figure 7.

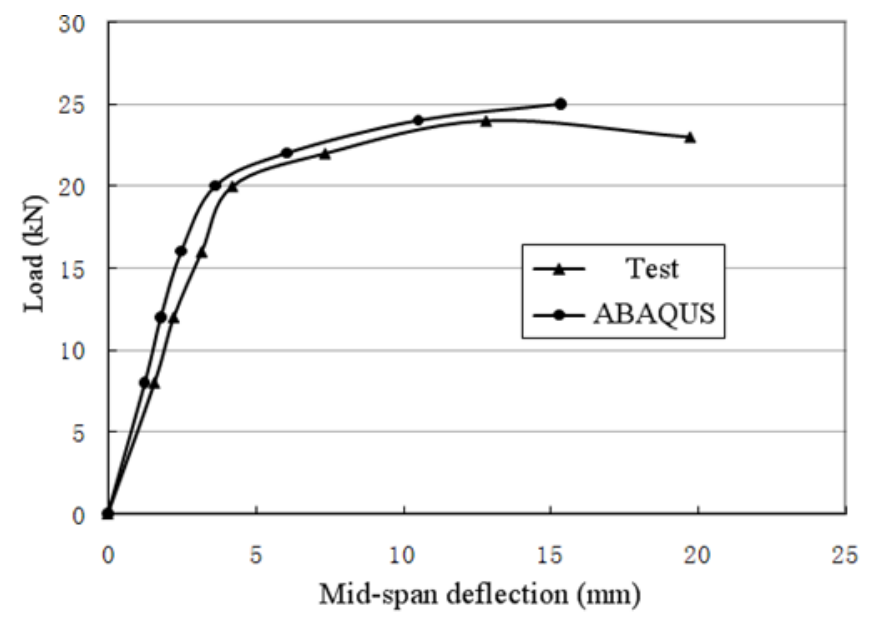

Figure 7 mid-span deflection value comparison chart

As can be seen from Figure 7, the varying trends of mid-span deflection with load of ABAQUS and test results are the same. Before $8 \mathrm{kN}$ of load, the beam is in elastic stage with high stiffness and strength, load values varying linearly with the deflection. And then, it came into the plastic stage, deflection value adding accelerated. When the load reached the capacity of $24 \mathrm{kN}$, the value of mid-span deflection is $10.521 \mathrm{~mm}$ of ABAQUS and $12.795 \mathrm{~mm}$ of test. In the last, the beam failure. It can be seen that ABAQUS can be basically consistent with the actual test results, but there are also differences between the values calculated by the analysis and the test. The reason may be the following:

(1) Finite element simulations is assumed to have a uniform, isotropic and the same contact form between cells, however, the constitution of actual concrete is very complex, including cement, sand, gravel and so on. The Complicated action between them can not be easily replaced by unified form.

(2) In Finite Element Analysis, bond between concrete and steel is processed using the Embedded Technology, effectively simplifying the modeling, but it can not be achieved with the increased load of reinforced concrete and changing nature of the friction moment, especially reinforced slip simulation. This can easily lead to distorted results.

(3) Other factors also affect the results of the analysis such as convergence of Finite Element Analysis, reasonableness of simulation parameter values, form and quantity of finite element division and casting quality and loading conditions of beam in test. 
In short, finite element analysis simulation test of reinforced concrete has a high degree of similarity with actual situation: despite some differences, the finite element method for nonlinear analysis of beam test is feasible.

\section{Summary}

This paper talked about the reasons of differences between the results of numerical analysis and test. In this paper, we used software ABAQUS to imitate the test of beam: by adopting the model of concrete damaging and the technology of embedded between steel bar and concrete, we got similar results with actual test. All those above prove that the finite element software ABAQUS is effective enough, but how to get exacter results deserves further exploration.

\section{Acknowledgements}

This research is sponsored by BUCEA Urban Rural Construction and Management Industry Research Development Collaboration Post Graduate Training Centre.

\section{References}

[1] LIU Jing-song, LIU Hong-jun. ABAQUS Finite Element Analysis of Reinforced Concrete [J]. EQUIPMENT MANUFACTURING TECHNOLOGY, 2009,(6):69-70,107.

[2] LV Xi-lin, JIN Guo-fang, WU Xiao-han. Reinforced Concrete Structure Nonlinear Theory and Applications [M]. Shanghai: Tongji University Press, 1997: 55-67.

[3] ZHUANG Zhuo, ZHANG Fan, CEN Song. ABAQUS Nonlinear Finite Element Analysis and Examples[M]. Beijing: Science Press, 2005:123-139.

[4] ABAQUS Analysis User’'s Manual, ABAQUS Inc, 2006.

[5] Southeast University etc. Concrete Structure Design Theory[M]. Beijing: China Building Industry Press, 2008.

[6] Design Principle of Concrete Structures, GB50010 - 2010.

[7] JIANG Jian-jing, LU Xin-zheng, YE Lie-ping. Finite Element Analysis of Concrete Structures [M]. Beijing: Tsinghua University Press, 2005.

[8] ZHANG Guo-li, SU Jun. Based on ABAQUS Nonlinear Analysis of Reinforced Concrete [J]. SCIENCE TECHNOLOGY AND ENGINEERING, 2008,8(20):5620-5624. 